\title{
Changes in Free Amino Acid Content in the Flesh and Peel of 'Cavendish' Banana Fruit as Related to Branched-chain Ester Production, Ripening, and Senescence
}

\author{
Nihad Alsmairat \\ Department of Horticulture and Crop Science, The University of Jordan, Amman 11942, Jordan \\ Philip Engelgau and Randolph Beaudry ${ }^{1}$ \\ Department of Horticulture, Michigan State University, 1066 Bogue Street, East Lansing, MI 48824
}

AdDitional INDEX words. leucine, valine, isopropylmalate synthase, IPMS, citramalate, alpha-keto acid

\begin{abstract}
The concentrations of free amino acids in the peel and pulp of banana (Musa sp., AAA group, Cavendish subgroup, cv. Valery) fruit during ripening at $22{ }^{\circ} \mathrm{C}$ were measured. All 20 amino acids were quantified at seven distinct ripening stages as defined by measures of internal ethylene, $\mathrm{O}_{2}$, and $\mathrm{CO}_{2}$ concentrations, aroma volatile emissions, and peel color. Volatile production commenced 2 days after the peak in ethylene production and 1 day following the climacteric peak in internal $\mathrm{CO}_{2}$. The maximum rate of branched-chain ester synthesis occurred 2 to 3 days after its onset. Production of 2-methylpropyl and 3-methylbutyl esters was much higher in the pulp compared with the peel, confirming that the pulp, rather than the peel, is the primary site of banana aroma synthesis. Of the amino acids measured, only leucine, valine, and cysteine increased concomitantly with ester formation. This was observed in the pulp, but not in the peel. The data suggest the metabolic pathways for valine and leucine formation also support, respectively, the synthesis of 2-methylpropyl and 3-methylbutyl esters. It is not clear how leucine and valine can accumulate despite the fact that they act as feedback inhibitors of their respective synthetic pathways. There was a slight peak in the formation of several other amino acids in the pulp (e.g., alanine, arginine, asparagine, glutamine, and methionine) coinciding with the climacteric respiratory peak in $\mathrm{CO}_{2}$, but a similar pattern was not seen for the peel. These data are the first to demonstrate distinct differences in amino acid metabolism in the peel and pulp of banana related to their role in ripening and aroma biosynthesis.
\end{abstract}

The synthetic and/or catabolic pathways of the amino acids valine, leucine, isoleucine, methionine, phenylalanine, and alanine contribute to the formation of odor-active alcohols, aldehydes, carbonyls, and esters in edible plant parts (Azevedo et al., 1997; Baldwin et al., 2002: Gonda et al., 2010; Pérez et al., 1992; Reineccius, 2006; Salunkhe and Do, 1976; Sanz et al., 1997). Further, other amino acids act as precursors to these odorcontributing amino acids. Aspartate, for instance, is consumed in the synthesis of several amino acids including lysine, methionine, and threonine, the latter of which is a precursor to isoleucine (Azevedo et al., 1997).

Branched-chain (BC) esters are important contributors to the fruity aroma of several important horticultural crops. The pathway for their formation has been previously described (Fig. 1), but new aspects continue to emerge. In apple (Malus $\times$ domestica) fruit, for instance, 2-methylbutyl ester accumulation during ripening is associated with the increased synthesis of citramalic acid, which may contribute to a new pathway for

Received for publication 15 June 2018. Accepted for publication 9 Aug. 2018. The authors would like to acknowledge the financial support of the Michigan Agricultural Experiment Station (AgBioResearch), the National Institute of Food and Agriculture, and the University of Jordan. This work was inspired by conversations with Jun Song and Fritz Bangerth, who rightly predicted that de novo biology was required for the formation of aroma compounds in ripening fruit.

${ }^{1}$ Corresponding author. E-mail: beaudry@msu.edu.

This is an open access article distributed under the CC BY-NC-ND license (http://creativecommons.org/licenses/by-nc-nd/4.0/). isoleucine and $\mathrm{BC}$ ester synthesis in apple (Sugimoto et al., 2011, 2015). In banana fruit, the amino acids valine and leucine have been proposed to be used, respectively, in the formation of 2-methylpropyl and 3-methylbutyl esters (Tressl and Jennings, 1972), which account for about $70 \%$ of the volatile compounds produced by banana (Seymour, 1993).

Fruit esters are formed by the reaction between alcohols and acyl CoA derivatives of carboxylic acids. Labeling studies for BC esters have shown that leucine feeding yields 3-methylbutanol and 3-methylbutanoate, which can then be used to form 3-methylbutyl esters (e.g., 3-methylbutyl acetate, 3-methylbutyl butanoate, ethyl 3-methylbutanoate, butyl 3-methylbutanoate, and 3-methylbutyl 3-methylbutanoate); valine feeding produces 2-methylpropanol and 2-methylproponoate and their ester derivatives; isoleucine feeding yields 2-methylbutanol and 2-methylbutanoate and their ester derivatives (Pérez et al., 2002; Rowan et al., 1996, 1998; Tressl and Drawert, 1973; Wyllie and Fellman, 2000; Wyllie et al., 1996).

The banana ester profile has several 3-methylbutyl esters and a smaller number of 2-methylpropyl esters arising, respectively, from the pathways leading to the synthesis of leucine and valine (Tressl and Jennings, 1972; Wyllie and Fellman, 2000). Of these esters, 3-methylbutyl butanoate is the predominant ester of 'Cavendish' banana (Nogueira et al., 2003) and it acts with 3-methybutyl acetate and 3-methylbutyl 3-methylbutanoate to constitute the core components of the characteristic odor of ripened banana fruit (Jordan et al., 2001; Quast, 1976; Schiota, 1993). 


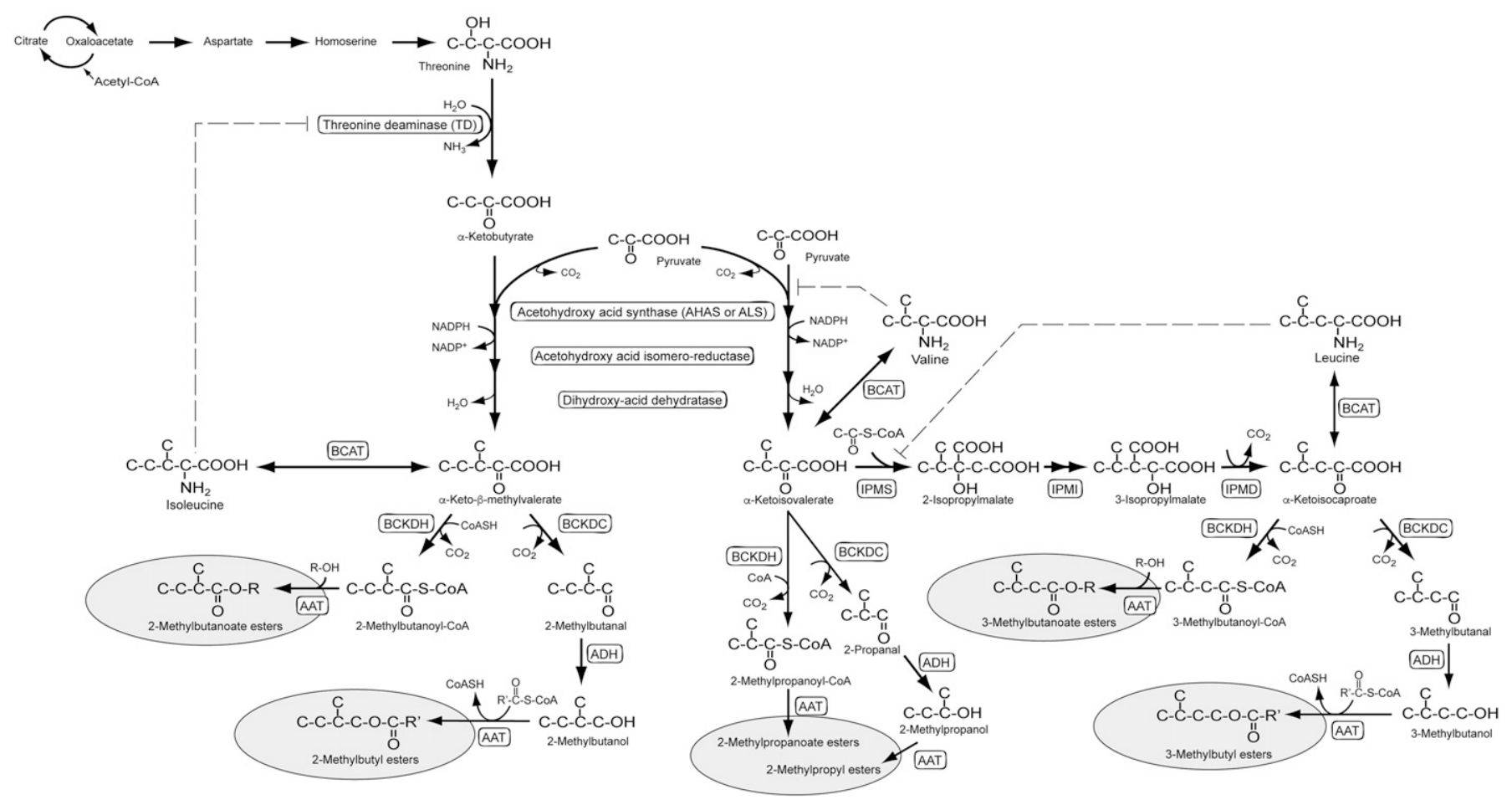

Fig. 1. Pathways involved in branched-chain ester biosynthesis (adapted from Sugimoto et al., 2015). Dashed lines indicate feedback inhibition; BCAT $=$ branchedchain amino transferase, $\mathrm{ADH}=$ alcohol dehydrogenase, $\mathrm{AAT}=$ alcohol acyl-CoA transferase, IPMS $=$ isopropylmalate synthase, IPMI $=$ isopropylmalate isomerase, IPMD $=$ isopropylmalate decarboxylase, $\mathrm{BCKDH}=$ branched-chain $\alpha$-keto acid dehydrogenase, $\mathrm{BCKDC}=$ branched-chain $\alpha$-keto acid decarboxylase.

Pools of free $\mathrm{BC}$ amino acids accumulate during ripening of apple, banana, melon (Cucumis melo), and strawberry (Fragaria $\times$ ananassa) fruit (Pérez et al., 2002; Schieberle et al., 1990; Sugimoto et al., 2011; Tressl and Drawert, 1973; Yoshioka et al., 1982) and largely reflect the different $\mathrm{BC}$ aroma profile patterns found in those fruit. However, it is relevant to note that these $\mathrm{BC}$ amino acids are not directly converted to the alcohol and acid precursors of $\mathrm{BC}$ esters. Rather, the $\mathrm{BC} \alpha$-keto precursors to isoleucine, valine, and leucine (i.e., $\alpha$-keto$\beta$-methylvalerate, $\alpha$-ketoisovalerate, and $\alpha$-ketoisocaproate, respectively) are positioned more directly in the pathway of ester formation (Sugimoto et al., 2011) (Fig. 1). Tewari et al. (2000) noted that the BC $\alpha$-keto acids are in approximate equilibrium with their respective $\mathrm{BC}$ amino acids, suggesting that the pools of $\mathrm{BC}$ amino acids mirror the pools of their respective $\alpha$-keto acid precursors. In fact, $\mathrm{BC}$ esters can be produced directly from exogenously supplied BC $\alpha$-keto acids (Gonda et al., 2010). Notably, in apple, there was no upregulation in 10 branched-chain aminotransferase (BCAT) genes during ripening (Sugimoto et al., 2008, 2011), suggesting a lack of regulation at the point of interconversion of $\mathrm{BC}$ amino acids and their respective $\mathrm{BC} \alpha$-keto acid precursor. Additionally, $\mathrm{BC} \alpha$-keto decarboxylase and $\mathrm{BC} \alpha$-keto dehydrogenase activities may also be important limiting steps in the interconversion of the $\mathrm{BC} \alpha$-keto acid pools to ester precursors (Gonda et al., 2010; Sugimoto et al., 2008, 2011).

In apple, the greater portion of aroma biosynthesis occurs in the peel (Guadagni et al., 1971). However, the relationship between banana peel and aroma production is less clear. Ji and Srzednicki (2015) found that the peel of ripe banana emitted many of the same volatiles produced by the pulp, with the most abundant esters being 3-methylbutyl acetate and 3-methylbutyl butanoate. However, multiple stages of ripening were not evaluated and the production of aroma compounds by the pulp was not determined in this study. Emaga et al. (2007) documented total amino acid concentrations of the banana peel, but did not evaluate free amino acid pools. They found little change in the content of total amino acids during ripening. Thus, the relationship between the free amino acid pools and aroma formation in the peel is not known. If the relationship between the $\mathrm{BC}$ esters and free $\mathrm{BC}$ amino acid pools mirrors that of the pulp, the finding will help bolster the linkage between $\mathrm{BC}$ amino acid metabolism and $\mathrm{BC}$ ester formation. Even more to the point, while we believe that amino acid metabolism is related to the synthesis of the BC esters responsible for "banana" aroma, this is not known conclusively. Further, we do not know the details of the regulation of the pathways for their synthesis.

To our knowledge, detailed information about the concentration of free amino acids in banana fruit peel and pulp during ripening is not available. Most studies on fruit pulp aroma and free amino acid content report only one or two stages of development. This is, in part, due to challenges previously associated with analysis. Current high-throughput methods combining high-performance liquid chromatography (HPLC) with multiple reaction monitoring of selected mass spectra ions facilitate additional scrutiny of metabolites like amino acids. The aim of this work was to more precisely describe the relationship between the physiological measures of ripeness (e.g., internal ethylene, $\mathrm{O}_{2}$ and $\mathrm{CO}_{2}$ concentrations, aroma volatile formation, and peel color) and free amino acid content of the peel and pulp than has been previously accomplished for 
ripening fruit. This work expands on previous work detailing the ontogeny of aroma formation by whole fruit relative to the onset of autocatalytic ethylene formation (Jayanty et al., 2002).

\section{Materials and Methods}

Plant material. Hands of mature green banana (Musa spp. AAA group, Cavendish subgroup, cv. Valery) from Honduras were obtained from a local produce distribution and ripening center (Chiquita ripening facility at Meijers, Lansing, MI). Fruit were obtained on the day of their receipt at the facility and before exposure to ethylene. Glass cylinders $(1.7-\mathrm{mL})$ fitted with rubber serum stoppers were attached to the surface of the fruit using a non-corrosive silicone rubber sealant (3140 RTV; Dow-Corning, Midland, MI) for the measurement of internal $\mathrm{O}_{2}, \mathrm{CO}_{2}$, and ethylene levels as previously described (Beaudry et al., 1987). After affixing the glass cylinders, fruit were covered by dark plastic trash bags to minimize moisture loss and to reduce incident light. The ethylene level in the cylinders was determined two or three times per day and analyzed as described below. Fruit were allowed to ripen at ambient temperature $\left(22^{\circ} \mathrm{C}\right)$. When the ethylene level was determined to be $2 \mathrm{~d}$ before peak in ethylene synthesis (day -2$)$, the day of the ethylene peak (day 0); and 1, 2, 3, 4, and $5 \mathrm{~d}$ past the peak in ethylene production (day 1, 2, 3, 4, and 5, respectively), additional sampling was performed. This procedure was used to identify fruit for two experiments. In Expt. 1, the content of amino acids was determined for peel and pulp. In Expt. 2, the production of volatiles from excised tissue of peel and pulp was determined.

Experiment 1. On each date, the $\mathrm{O}_{2}$ and $\mathrm{CO}_{2}$ levels in the cylinders were determined (described below), the volatile production of the intact fruit was determined (described below) and the amino acid content of the peel and pulp was determined (described below).

EXPERIMENT 2. In a related study, we attempted to determine the relative contribution of the peel, the outer pulp, and the inner pulp of ripening banana fruit to ester biosynthesis. For this, banana fruit were evaluated over $3 \mathrm{~d}$ (successive) with three fruit evaluated on each date. The experiment was repeated once using two lots of fruit acquired 2 weeks apart; one lot was slightly less ripe than the other. For each fruit, 10-mm diameter discs of pulp (inner and outer pulp) and peel were excised from the middle of the fruit using a stainless steel cork borer. For lot 1 (early), fruit were sampled on days 2, 3, and 4; for lot 2 (late), fruit were sampled on days 3, 4, and 5. The skin was used intact and the pulp disk was cut to a thickness of $4 \mathrm{~mm}$. The discs were placed singly onto wetted $15-\mathrm{mm}$ diameter filter discs supported by glass slides. The glass slides were placed into 22-mL glass vials possessing a gas-tight septum and valve (Mininert valve; Supelco, Bellefonte, PA), incubated for 15 min, and the volatiles in the headspace were determined as noted below.

INTERNAL $\mathbf{O}_{2}$ AND $\mathbf{C O}_{2}$. A 0.1-mL gas sample was withdrawn from the attached vials using a $0.5-\mathrm{mL}$ plastic insulin syringe and injected into an IR gas analyzer (model 225-MK3; Analytical Development Co., Hoddesdon, UK) and paramagnetic oxygen analyzer (Series 1100; Servomex Co., Crowborough, UK) linked in series and operated in a flow-through mode with $\mathrm{N}_{2}$ as the carrier gas $\left(150 \mathrm{~mL} \cdot \mathrm{min}^{-1}\right)$ as previously described (Beaudry et al., 1992). The gas concentrations were calculated using a certified gas standard (Matheson Gas
Products, Montgomeryville, PA) containing $0.979 \mu \mathrm{L} \cdot \mathrm{L}^{-1}$ ethylene, $4.85 \% \mathrm{CO}_{2}$, and $1.95 \% \mathrm{O}_{2}$, balanced with $\mathrm{N}_{2}$.

INTERNAL ETHYLENE. A $1-\mathrm{mL}$ gas sample was removed through the rubber septum of the cylinders attached to the fruit surface using a plastic syringe and was injected into a gas chromatograph (GC; Carle Series 400 AGC; Hach Co., Loveland, CO). The GC was fitted with a 6-m long, 2-mm i.d. stainless-steel column packed with activated alumina F-1 (80/ $100 \mathrm{mesh}$ ) and was equipped with flame ionization detector. The ethylene detection limit was $\approx 0.005 \mu \mathrm{L} \cdot \mathrm{L}^{-1}$. Ethylene concentrations were calculated using the certified standard noted previously.

Peel Color. Peel color was evaluated at three locations along the length of each fruit with a colorimeter (model 400 Chromameter; Minolta, Ramsay, NJ). The lightness (L), chroma $(\mathrm{C})$, and hue $\left(\mathrm{H}^{\circ}\right)$ color system was used to evaluate color. The colorimeter was calibrated before use with a standard white ceramic tile and the Yxy color system $(\mathrm{Y}=93.84, \mathrm{x}=$ $0.3132, \mathrm{y}=0.3191)$.

Volatile AnAlysis. Five banana fruit fingers were selected at each development stage and the fruit were placed individually in sealed glass containers $(600 \mathrm{~mL})$ at room temperature $\left(\approx 22{ }^{\circ} \mathrm{C}\right)$ and the chambers were agitated using a gently oscillating shaker operated at $60 \mathrm{rpm}$. Headspace volatiles were sampled after $15 \mathrm{~min}$ incubation using solid-phase micro extraction (SPME) fiber (65 $\mu \mathrm{m}$ PDMS-DVB) as previously described (Sugimoto et al., 2011). The SPME fiber was inserted in the jar septum port for 2 min to absorb headspace volatiles. The volatile compounds trapped in the SPME fiber were desorbed directly into a gas chromatograph (HP-6890; Hewlett-Packard, Wilmington, DE) using a splitless injection port heated to $230{ }^{\circ} \mathrm{C}$ and desorbed for $2 \mathrm{~min}$. Volatiles were trapped at the head of the column by immersion of the column in a pool of liquid $\mathrm{N}_{2}$. Release from the trap was by removal of the column from the liquid $\mathrm{N}_{2}$. The column starting temperature was $40{ }^{\circ} \mathrm{C}$; temperature was ramped at $40^{\circ} \mathrm{C} \cdot \mathrm{min}^{-1}$ to $240{ }^{\circ} \mathrm{C}$ and held for $1 \mathrm{~min}$. The $\mathrm{GC}$ was equipped with a mass selective detector (Pegasus II; LECO, St. Joseph, MI) for quantification and identification of volatiles.

Compound identification was by comparison of the retention time and mass spectrum with authenticated reference standards and with spectra in the National Institute of Standards and Technology (NIST) mass spectral library (Search Version 1.5) (NIST, 2011). Volatile compounds were quantified by calibrating with known amount of a mixture of authenticated, neat compounds (Sigma-Aldrich Co., St. Louis, MO and Fluka Chemika, Seelze, Germany) comprised of 20 alcohols, aldehydes, and esters as reported by Contreras et al. (2015). From the standard mixture, $1 \mu \mathrm{L}$ of the oil mixture was applied to a piece of filter paper, which was placed in a glass 4-L volumetric flask fitted with specially made ground glass stopper possessing a gas-tight septum and valve (Mininert valve, Supelco). The flask was held overnight at room temperature before use to permit the compounds to fully vaporize from the filter paper. Volatile quantities are reported as the response of the mass spectrometer, which was calculated as the total ion count (TIC) for each compound.

Amino ACID EXtraction. For each sampling date, a $1-\mathrm{cm}$ wide transverse slice from the middle portion of the five banana fruits used for volatile analysis was excised and the pulp and skin separated; from these tissues, two technical replicates were created. Tissues were immediately immersed in liquid nitrogen 
and then placed in 50-mL sealable plastic conical centrifuge tubes and held at $-80{ }^{\circ} \mathrm{C}$ until analysis. Before extraction, the frozen tissue was ground to a powder using a liquid $\mathrm{N}_{2}$-cooled ceramic mortar and pestle. For extraction, $0.5 \mathrm{~g}$ of the frozen powder was added to $2 \mathrm{~mL}$ of a solution of acetonitrile, ethanol, and water $(1: 1: 1)$ containing $10 \mu \mathrm{M}$ deuterated phenylalanine (Phe- $d_{8}$; Cambridge Isotope Laboratories, Andover, MA) as an internal standard. The extraction solution was preheated in water bath at $75^{\circ} \mathrm{C}$ for $5 \mathrm{~min}$. The mixture was vortexed for $10 \mathrm{~s}$ and incubated for $10 \mathrm{~min}$ at $75{ }^{\circ} \mathrm{C}$. After centrifugation (Damon/IEC PR-6000; Thermo Fisher Scientific, Waltham, MA) at $5000 g_{n}$ for $10 \mathrm{~min}$ at $4{ }^{\circ} \mathrm{C}$, a $600-\mu \mathrm{L}$ aliquot of the supernatant was transferred to a $1.5-\mathrm{mL}$ microfuge tube for additional clarification by further centrifugation (Micromax $\mathrm{RF}$, Thermo Fisher Scientific) at $14,000 \mathrm{~g}_{\mathrm{n}}$ for $10 \mathrm{~min}$ at $4{ }^{\circ} \mathrm{C}$. From the extract, $300 \mu \mathrm{L}$ was transferred to a $500-\mu \mathrm{L}$ centrifugal filter [0.2 $\mu \mathrm{m}$ (Spin-X; Corning, Corning, NY)] pre-wetted with $50 \mu \mathrm{L}$ extraction solution containing the internal standard and centrifuged for $5 \mathrm{~min}$ at $2000 \mathrm{~g}_{\mathrm{n}}$ at $4{ }^{\circ} \mathrm{C}$. Analysis was performed on an aliquot $(20 \mu \mathrm{L})$ of the filtrate diluted 8.5 -fold by adding it to $230 \mu \mathrm{L}$ of the extraction solution containing the internal standard.

Amino ACID Analysis. A mixture of 20 amino acids (SigmaAldrich) were dissolved in water containing $10 \mu \mathrm{M}$ Phe- $d_{8}$ to make individual stock solutions of $1 \mathrm{~mm}$. Amino acids were analyzed according to Sugimoto et al. (2011) and Phe- $d_{8}$ as noted in Table 1 using a tandem mass spectrometer (Quattro micro; Waters, Milford, MA) coupled to a high-pressure liquid chromatograph (LC-20AD HPLC; Shimadzu, Columbia, MD). Data were collected and quantified with proprietary software

Table 1. The HPLC/MS/MS conditions for deuterated phenylalanine (Phe- $d_{8}$ ) were optimized for mass to charge number of ions ratio $(\mathrm{m} / \mathrm{z})$, cone voltage, collision voltage, and retention time. HPLC and MS/MS conditions for amino acids were as reported for Sugimoto et al. (2011).

\begin{tabular}{lccccc}
\hline & $\begin{array}{l}\text { Mass of } \\
\text { parent }> \\
\text { daughter } \\
\text { ions }(m / z)\end{array}$ & $\begin{array}{c}\text { Cone } \\
\text { voltage }\end{array}$ & $\begin{array}{c}\text { Collision } \\
\text { voltage }\end{array}$ & $\begin{array}{c}\text { Retention } \\
\text { time } \\
\text { Compound }\end{array}$ & $\begin{array}{c}\text { Function } \\
(\mathrm{Vin})\end{array}$ \\
\hline Phe- $d_{8}$ & $174.0>128.0$ & 18 & 15 & 3.2 & 2 \\
\hline
\end{tabular}

(MassLynx 4.0 and QuanLynx, Waters). Amino acid samples were quantified by calibration curves obtained from six working standards using linear regression, plotting amino acid concentration as a function of ratio of the amino acid peak area to the Phe- $d_{8}$ peak area.

\section{Results and Discussion}

Maturation indices. Ethylene concentration was near the limit of detection $\left(5 \mathrm{~nL} \cdot \mathrm{L}^{-1}\right) 2 \mathrm{~d}$ before peak in autocatalytic ethylene production, increasing to $\approx 0.1 \mu \mathrm{L} \cdot \mathrm{L}^{-1}$ on day -0.5 and to $4 \mu \mathrm{L} \cdot \mathrm{L}^{-1}$ at the climacteric peak (day 0 ). Carbon dioxide levels in the fruit doubled from day -2 to day 0 and continued to increase until day 1. Subsequently, the $\mathrm{CO}_{2}$ concentration decreased slightly from day 2 to day 5 . The data for ethylene and $\mathrm{CO}_{2}$ were consistent with previously published studies (Beaudry et al., 1987, 1989; Jayanty et al., 2002). The hue $\left(\mathrm{H}^{\circ}\right)$ of the fruit skin decreased throughout ripening (Fig. 2) as the fruit changed from green $\left(\mathrm{H}^{\circ} 115\right)$ to yellow $\left(\mathrm{H}^{\circ} 85\right)$. Lightness and chroma increased until day 3 and 4 and declined thereafter as sugar spots formed.

Ester emanations. The BC volatiles quantified (3methylbutanol, 2-methylpropanol, 3-methylbutyl acetate, 2methylpropyl butanoate, 3-methylbutyl butanoate, 2-methylpropyl acetate and 3-methylbutyl 3-methylbutanoate) were detected in small amounts or were not detectable day -2 through day 0 (Fig. 3). No 2-methylbutyl esters were detected. Three days after the ethylene peak, BC alcohol and BC ester biosynthesis increased rapidly. With the exception of 3-methylbutyl 3methylbutanoate, $\mathrm{BC}$ ester production peaked on day 4 . The production of the two $\mathrm{BC}$ alcohols increased throughout ripening, reaching their highest level on day 5. BC acetate esters were more abundant than $\mathrm{BC}$ butanoate esters and the least abundant ester measured was 3-methylbutyl 3-methylbutanoate (Fig. 3). The timing and the relative quantities of ester emanation were consistent with previous results for 'Cavendish' banana (Jayanty et al., 2002).

In excised tissue disks, those from more ripe fruit (late) produced greater quantities of $\mathrm{BC}$ alcohols and esters than disks from less ripe fruit (early) (Table 2), suggesting that the emanations from tissue disks behaved similarly to whole fruit. The ester profiles for peel and pulp were similar, which is

Table 2. Emanation of branched chain alcohols and esters from discs of ripening banana peel and inner and outer pulp incubated for 15 min at $20{ }^{\circ} \mathrm{C}$ in $22-\mathrm{mL}$ glass chambers. Data are averages for banana fruit over $3 \mathrm{~d}$ (successive), taken 2, 3, and $4 \mathrm{~d}$ (early) or 3, 4, and $5 \mathrm{~d}$ (late) after the peak in ethylene biosynthesis. Three replicate fruit samples were taken for each ripeness/tissue type combination on each day.

\begin{tabular}{|c|c|c|c|c|c|c|c|c|c|c|c|c|c|c|}
\hline \multirow[b]{2}{*}{ Main effect } & \multicolumn{2}{|c|}{$\begin{array}{c}\text { 2-M } \\
\text { propanol }^{\mathrm{z}}\end{array}$} & \multicolumn{2}{|c|}{$\begin{array}{c}\text { 3-M } \\
\text { butanol }\end{array}$} & \multicolumn{2}{|c|}{$\begin{array}{c}\text {-MP } \\
\text { acetate }\end{array}$} & \multicolumn{2}{|c|}{$\begin{array}{l}\text { 3-MB } \\
\text { acetate }\end{array}$} & \multicolumn{2}{|c|}{$\begin{array}{c}\text { 2-MP } \\
\text { butanoate }\end{array}$} & \multicolumn{2}{|c|}{$\begin{array}{c}\text { 3-MB } \\
\text { butanoate }\end{array}$} & \multicolumn{2}{|c|}{$\begin{array}{l}\text { 3-MB 3-M } \\
\text { butanoate }\end{array}$} \\
\hline & \multicolumn{14}{|c|}{$\left(\mu \mathrm{L} \cdot \mathrm{L}^{-1}\right)$} \\
\hline Outer pulp & 24.6 & $\mathrm{a}$ & 23.3 & $\mathrm{a}$ & 816.8 & $\mathrm{a}$ & 1009.7 & $\mathrm{a}$ & 80.9 & $\mathrm{a}$ & 127.3 & $\mathrm{a}$ & 2.9 & $\mathrm{a}$ \\
\hline Central pulp & 17.4 & $\mathrm{a}$ & 15.7 & $\mathrm{a}$ & 472.2 & $\mathrm{a}$ & 568.9 & $\mathrm{a}$ & 26.4 & $\mathrm{a}$ & 41.4 & $\mathrm{a}$ & 1.5 & $\mathrm{a}$ \\
\hline \multicolumn{15}{|l|}{ Ripeness } \\
\hline Late & 20.7 & $\mathrm{a}$ & 21.9 & $\mathrm{a}$ & 691.5 & $\mathrm{a}$ & 833.3 & $\mathrm{a}$ & 65.7 & $\mathrm{a}$ & 89.1 & $\mathrm{a}$ & 2.2 & ns \\
\hline
\end{tabular}

${ }^{\mathrm{z}}$ 2-M propanol = 2-methylpropanol, 3-M butanol = 3-methylbutanol, 2-MP acetate $=$ 2-methylpropyl acetate, 3-MB acetate $=3$-methylbutyl acetate, 2-MP butanoate = 2-methylpropyl butanoate, 3-MB butanoate = 3-methylbutyl butanoate, 3-MB 3-M butanoate = 3-methylbutyl 3methyl butanoate.

${ }^{\mathrm{y}}$ Within tissue type and ripeness main effects, any two means within a column not followed by the same letter are significantly different at $P \leq 0.05$. Interactions were not tested. 

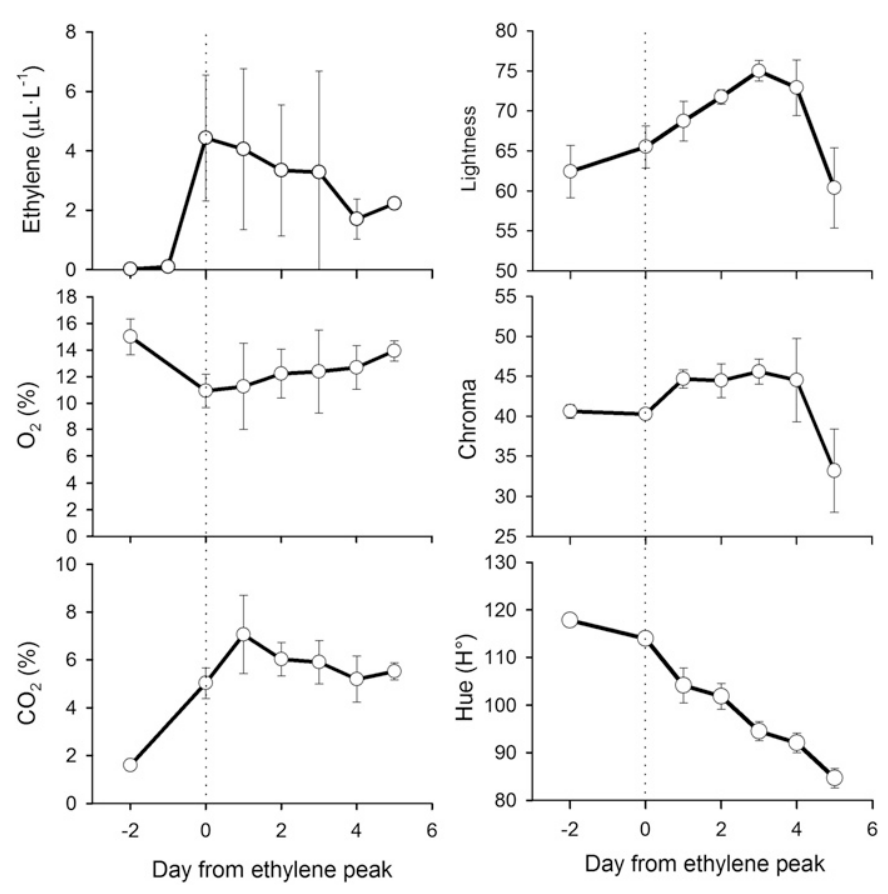

Fig. 2. Internal ethylene concentration, internal $\mathrm{O}_{2}$ fraction, internal $\mathrm{CO}_{2}$ fraction, and peel lightness, chroma, and hue of 'Cavendish' banana fruit at different fruit ripening stages. The vertical line on day 0 indicates the peak of ethylene biosynthesis. Each data point represents the average of five fruit; vertical bars represent \pm SE.

consistent with the findings of Ji and Srzednicki (2015); however, the pulp produced far more BC esters and $\mathrm{BC}$ alcohols than the peel, indicating that the pulp of the banana is the primary source of aroma compounds in ripening fruit. The dissimilar metabolic activities of these tissues during ripening is perhaps not surprising given the differential sensitivities of the peel and pulp to ethylene (Inaba et al., 2007). The lack of involvement of the peel of fruit in aroma formation is not unusual, but apple, which makes large amounts of BC esters, produces most of its aroma from the peel tissue (Ferreira et al., 2009; Guadagni et al., 1971). The data also suggest that the bulk of emanations from whole banana fruit likely diffuse through the fruit peel and may offer an opportunity for the peel to regulate the release of alcohols and esters. It is possible that esterases or alcohol acyl transferases in the peel could alter the volatile profile of intact fruit. There was no difference in the production of $\mathrm{BC}$ alcohols and esters between the outer and central pulp of the edible portion of the fruit, suggesting that $\mathrm{BC}$ amino acid and $\mathrm{BC}$ ester metabolism is relatively similar throughout the banana pulp.

Amino ACIDS. Patterns of change in amino acid content during fruit ripening were diverse in pulp (Fig. 4) and peel (Fig. 5) with some amino acids increasing or decreasing throughout ripening or undergoing transient accumulation or depletion. Patterns in the flesh did not necessarily reflect changes in the peel, with some ratios increasing or decreasing throughout ripening (Fig. 6). The amino acid concentration in pulp was lower than in the peel for 13 of the 20 amino acids.

In the pulp, only valine, leucine, and cysteine accumulated more than 3-fold after day 0 and continued to accumulate throughout ripening (Fig. 4). The relationship between cysteine metabolism and fruit ripening is not clear, but Ge et al. (2017) proposed a role for $\mathrm{H}_{2} \mathrm{~S}$, a breakdown product of cysteine, in the suppression of fruit ripening by reduction of oxidative stress and inhibition of the ethylene-signaling pathway. The accumulation of valine and leucine is likely related to $\mathrm{BC}$ ester formation. However, given that the BCAT enzymes carry out freely reversible reactions (Gonda et al., 2010), the accumulation of valine and leucine should reflect an increase in their respective $\alpha$-keto acid precursors (Fig. 1). This would be consistent with the increased flux of carbon into BC alcohols and esters during the latter stages of ripening. The lack of an increase in BC alcohols (and esters) during the early stages of ripening, despite small but significant increases in valine and leucine, is not consistent with this interpretation. It suggests that the flux into this pathway begins early (before ester formation), but that the diversion of the $\mathrm{BC} \alpha$-keto acids to their respective $\mathrm{BC}$ alcohols has yet to begin. Jayanty et al. (2002) demonstrated that the capacity for ester formation in banana tissue disks from exogenously applied $\mathrm{BC}$ alcohols and acids is fully engaged at the stage of peak ethylene production (day 0 ) and showed that transcription of alcohol acyltransferase (AAT) is evident well before this stage. Thus, the limitation is not through AAT activity. The suggestion, therefore, is that the limitation in the formation of $\mathrm{BC}$ esters during the first 1 to $2 \mathrm{~d}$ of banana ripening is due to a lack of the ability of the fruit to make $\mathrm{BC}$ alcohols and $\mathrm{BC}$ acids from the $\mathrm{BC} \alpha$-keto acids. The limitation may be due to insufficient $\mathrm{BC} \alpha$-keto decarboxylase and/or alcohol dehydrogenase activities. The importance of $\alpha$-keto decarboxylase activity has been noted for melon fruit (Gonda et al., 2010) and for apple (Sugimoto et al., 2011); however, much-needed molecular and enzymatic data for banana are lacking.

Several amino acids (alanine, arginine, asparagine, glutamate, glutamine, histidine, lysine, methionine, phenylalanine, proline, and tyrosine) in the pulp exhibited a modest to pronounced peak on day 2, $1 \mathrm{~d}$ after the highest internal $\mathrm{CO}_{2}$ concentration was recorded, reflecting the climacteric peak (Fig. 4). This may simply reflect a period of elevated metabolic activity and a concomitant increase in the pools of the amino acids needed for the production of new proteins needed for ripening (Brady et al., 1970). It is striking that the spikes in the content of these amino acids is limited, given the 2- to 3-fold increase in respiration experienced by banana fruit during this stage of ripening (Beaudry et al., 1987) and speaks to the robustness of the regulation of amino acid synthesis and degradation.

Aspartate, isoleucine, and phenylalanine content in the pulp declined during ripening, with the greatest decline occurring at the outset of ripening between day -2 and day 0 . In apple, isoleucine content increases markedly during ripening, concomitant with increasing 2-methylbutyl esters. The lack of accumulation of the $\mathrm{BC}$ amino acid isoleucine in banana is consistent with the lack of production of 2-methylbutyl esters, which are derived from the precursor to isoleucine, $\alpha$-keto $\beta$-methylvalerate. In apple fruit, it appeared that feedback inhibition by isoleucine is lacking, permitting its accumulation (Sugimoto et al., 2011, 2015). Sugimoto et al. (2011, 2015) suggested the isoleucine accumulation was accompanied by the induction of a pathway for isoleucine formation that was not feedback regulated by isoleucine and was initiated with the synthesis of citramalic acid, which accumulates in apple (Hulme, 1954; Sugimoto et al., 2015). This is opposed to the usual means of isoleucine synthesis via threonine degradation (Fig. 1). 

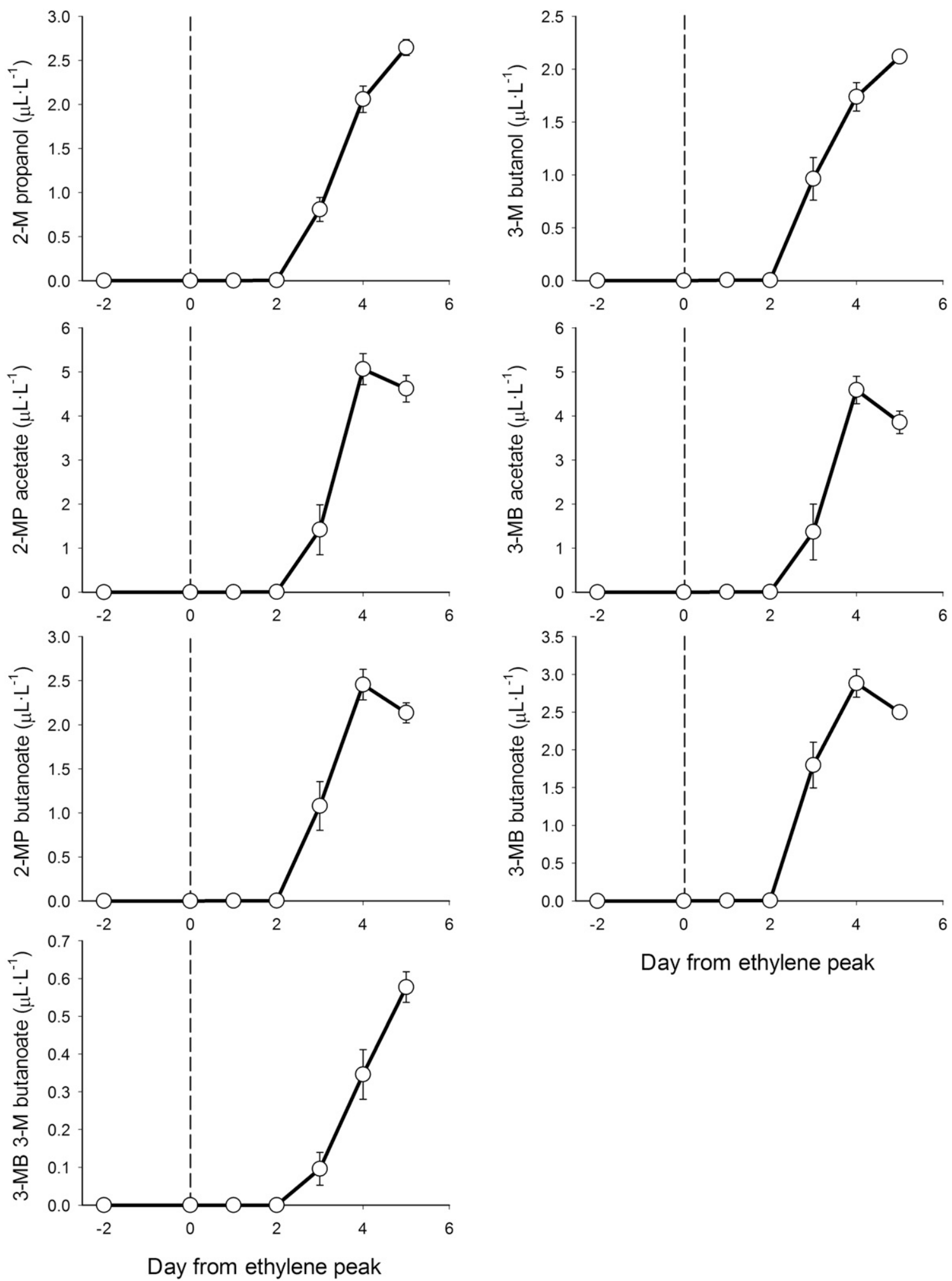

Day from ethylene peak

\section{Day from ethylene peak}

Fig. 3. Patterns of branched chain volatiles at different stage of fruit ripening for 'Cavendish' banana fruit. The vertical dashed line on day 0 indicates the peak of ethylene biosynthesis; 2-M propanol = 2-methylpropanol, 3-M butanol = 3-methylbutanol, 2-MP acetate $=2$-methylpropyl acetate, 3-MB acetate $=3$-methylbutyl acetate, 2-MP butanoate $=2$-methylpropyl butanoate, 3-MB butanoate $=3$-methylbutyl butanoate, 3-MB 3-M butanoate $=3$-methylbutyl 3-methyl butanoate . Each data point represents the average of five fruit; vertical bars represent $\pm \mathrm{SE}$.

The increase of free leucine and valine in ripening banana pulp seems to be analogous to the increase of free isoleucine in apple, suggesting that an alternative means of synthesis/regulation may be present in banana pulp. One would anticipate that the accumulation of both leucine and valine would inhibit their own formation unless the feedback mechanisms were somehow impaired in ripening banana. Acetohydroxy acid synthase (AHAS), also known as acetolactate synthase (ALS), is 

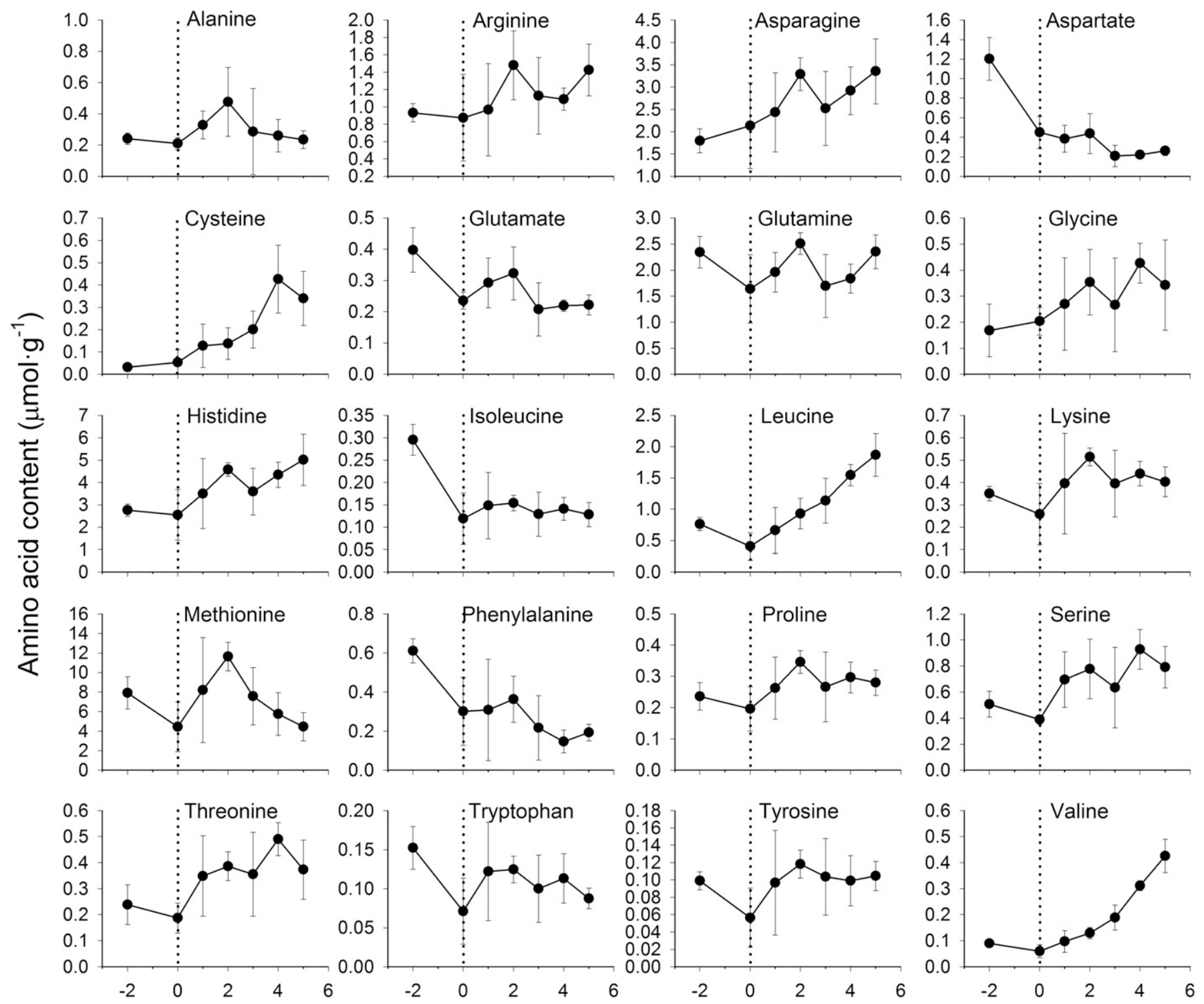

Day relative to ethylene peak

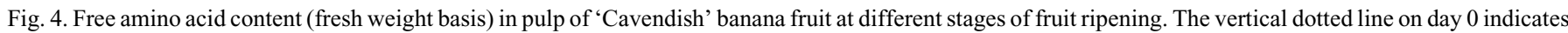
the peak of ethylene biosynthesis. Each data point represents the average of five fruit with two technical replicates per fruit; vertical bars represent \pm SE.

inhibited by valine and leucine, and isopropyl malate synthase (IPMS) is inhibited by leucine (Eisenstein, 1991; Singh and Shaner, 1995; Wessel et al., 2000). It is possible that feedbackimpaired isoforms of IPMS and/or ALS are present during ripening in banana pulp. Modifications of the feedback regulation of IPMS have been observed in several species, such as a mutant of yeast (Saccharomyces cerevisiae) that has had mutations within the regulatory region of yeast's isopropylmalate synthase, $L E U 4$, leading to an overproduction of 3methylbutanol and 3-methylbutyl acetate (Ogata and Miyashita, 2014). Neofunctionalization of IPMS, which has generated methylthioalkylmalate synthase (MAM) in Arabidopsis thaliana (de Kraker and Gershenzon, 2011), SlIPMS3 in tomato, an enzyme that affects the metabolism of branched-acyl chain attachments of acylsugars (Ning et al., 2015), and possibly 2-ethylmalate synthase, an enzyme capable of straight-chain $\alpha$-keto acid elongation (Kroumova and Wagner, 2002), is often accompanied with heavy modifications or truncation of the C-terminal feedback domain, which frees these enzymes of specialized metabolism from regulation by their products. While the process of neofunctionalization is characterized by gene duplication to preserve primary metabolism functions, the newest banana genome (Martin et al., 2016) appears to have only one copy of IPMS, unlike what is seen in most other plants, which have two IPMS copies (Xing and Last, 2017). However, the feedback regulatory region of banana IPMS seems to be quite divergent from the IPMS genes from apple and other fruit crops (data not shown). Collectively, these findings suggest that feedback regulation of IPMS may be complex or incomplete and it is possible that there is a developmentally regulated reduction in the sensitivity of IPMS to leucine levels, permitting increased flux to $\alpha$-ketoisocaproate and 3-methylbutyl 


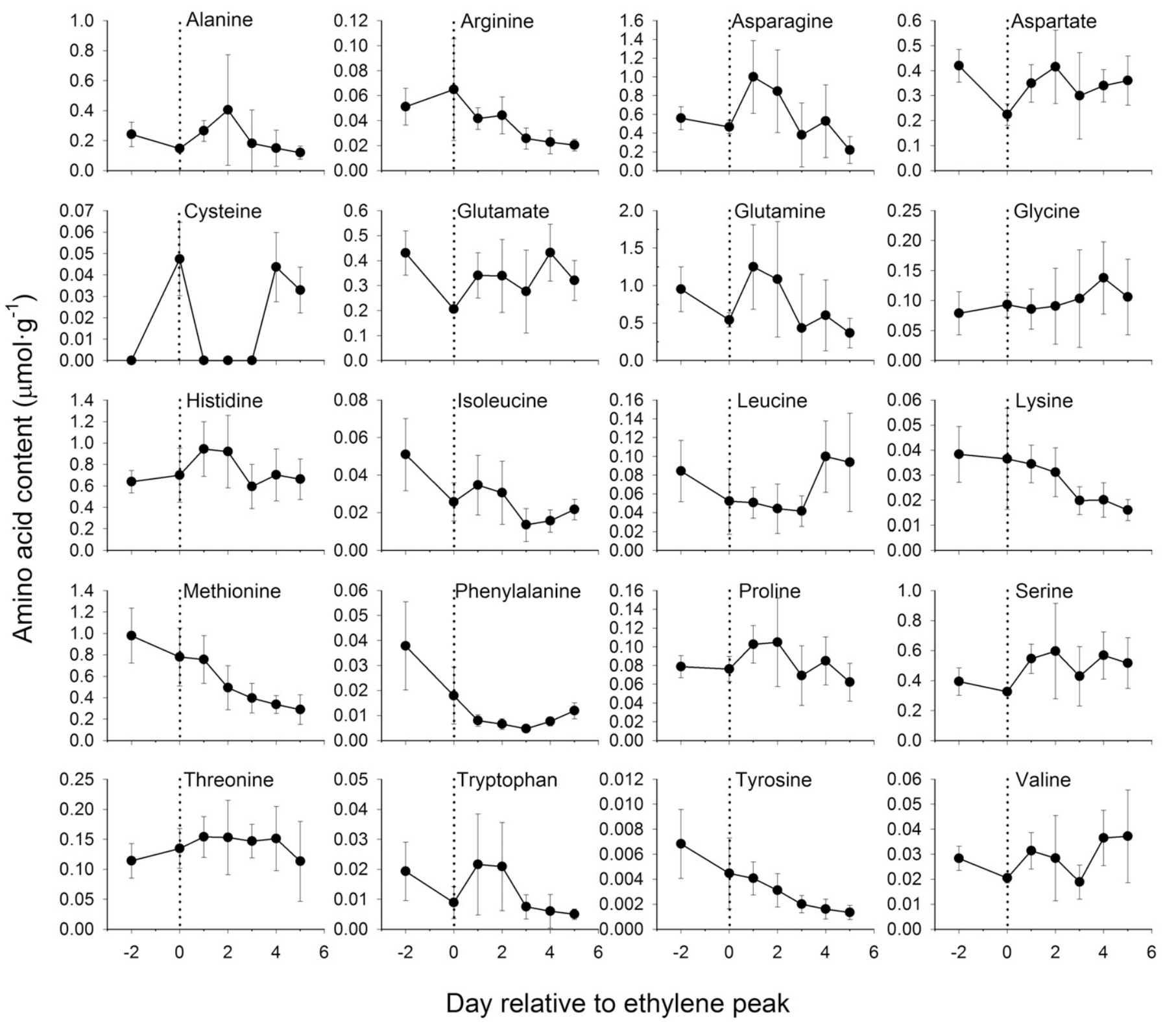

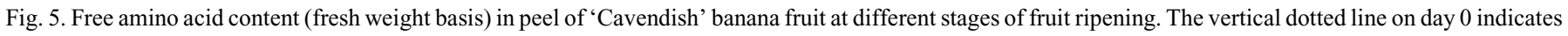
the peak of ethylene biosynthesis. Each data point represents the average of five fruit with two technical replicates per fruit; vertical bars represent \pm SE.

esters during ripening. Additional analysis of the banana genome and of protein function is required to assess this possibility.

Finally, the inhibition of threonine deaminase (TD) by isoleucine can promote the accumulation of threonine (Mourad and King, 1995). This suggests that the decline in isoleucine in banana should have been accompanied by a decline in threonine levels; however, the opposite was observed. However, TD also can be stimulated by valine (Eisenstein, 1991), which might account for the modest accumulation of threonine during ripening.

In the peel, none of the free amino acids accumulated more than 3 -fold during ripening. In the case of leucine and valine, this would suggest that biology of these amino acids differs between the two organs. Indeed, the lack of a significant increase in these two $\mathrm{BC}$ amino acids was accompanied by markedly lower ester formation in the peel relative to the pulp (Table 2). There appeared to be a modest increase in leucine at the latter stages of ripening (day 4 and day 5). In the tissue feeding study by Jayanty et al. (2002), substantial capacity to synthesize 3-methylbutyl acetate by the peel was only found at the later ripening stages associated with maximal ester production, which would be consistent with a late burst in $\mathrm{BC}$ amino acid synthesis and associated ester formation in the peel.

Marked declines took place in the peel content of methionine, phenylalanine, and tyrosine (Fig. 5). The parallel changes in phenylalanine and tyrosine may reflect a diminution in throughput through the shared pathways for their synthesis (Yoo et al., 2013). With the exception of alanine, the peak in some amino acids found in the pulp on day 2 was not evident in the peel. However, several amino acids (alanine, asparagine, aspartate, glutamine, isoleucine, histidine, proline, serine, 


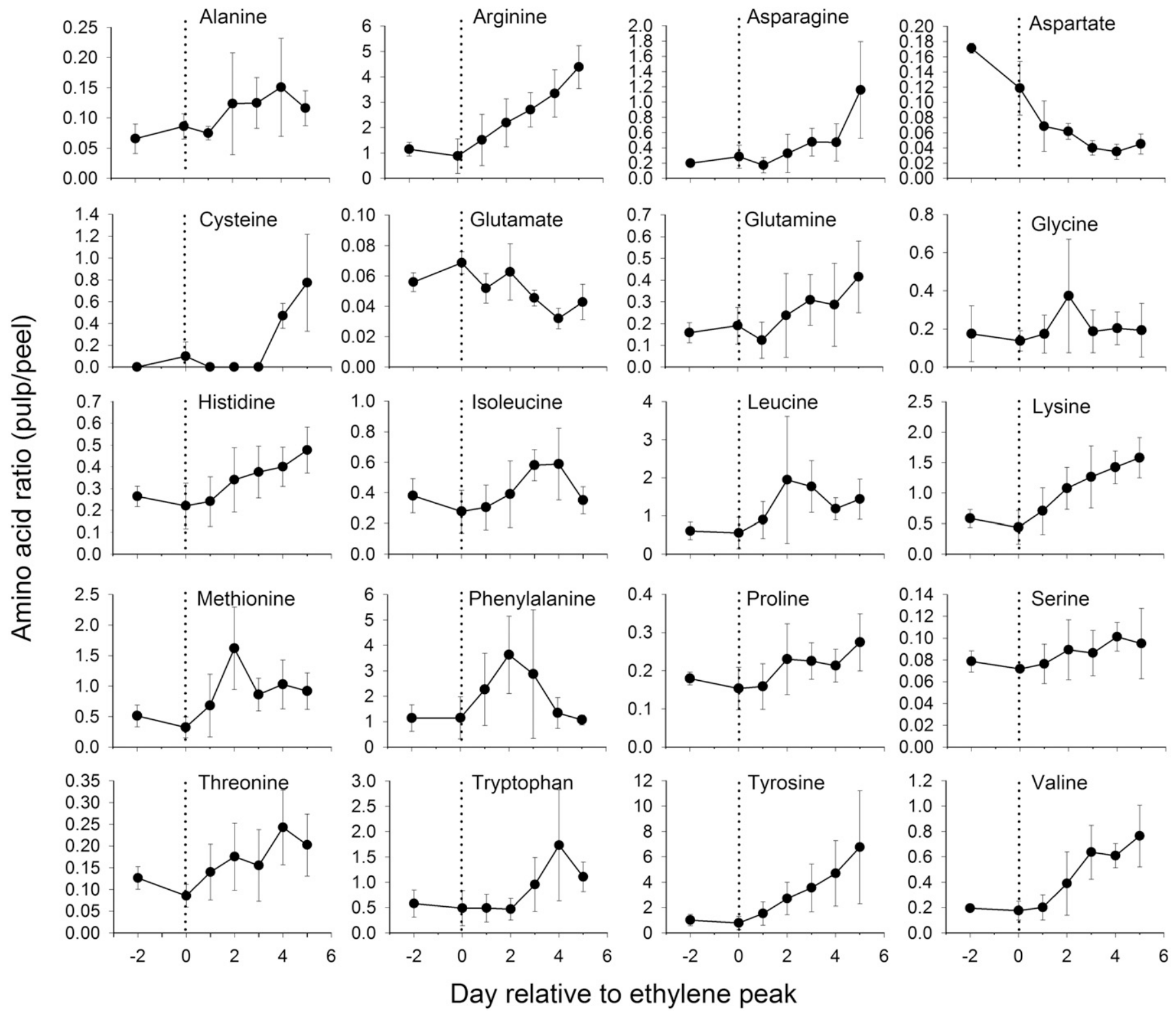

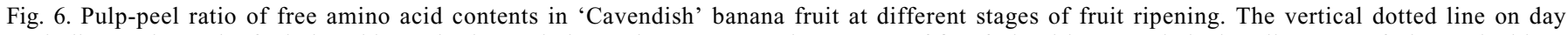
0 indicates the peak of ethylene biosynthesis. Each data point represents the average of five fruit with two technical replicates per fruit; vertical bars represent $\pm \mathrm{SE}$.

tryptophan, and valine) exhibited a short 2-day rise in content following the peak in ethylene production. The significance of this pattern is not known, although content of four of the amino acids (underlined) also peaked in the pulp during this period.

In conclusion, the data support a linkage between $\mathrm{BC}$ amino acid metabolism and $\mathrm{BC}$ ester formation in the pulp but not the peel of banana fruit. The data do not support the suggestion that already present $\mathrm{BC}$ amino acids are degraded to supply the $\mathrm{BC}$ $\alpha$-keto acid precursors necessary for $\mathrm{BC}$ ester synthesis (Gonda et al., 2010; Rowan et al., 1996). In fact, the opposite appears to be true, as both valine and leucine accumulate rather than decline during the phase of ester formation in banana. The same pattern of simultaneous $\mathrm{BC}$ amino acid accumulation and $\mathrm{BC}$ ester production is seen in apple also. Collectively, the data argue for an increase in the activity of the pathway leading to the formation of the $\mathrm{BC} \alpha$-keto acids required for the formation of both $\mathrm{BC}$ amino acids and $\mathrm{BC}$ esters, likely through upregulation of IPMS for 3-methylbutyl esters and AHAS for 2methylpropyl esters. Further, the data suggest that the increase of free BC amino acids is most likely a result of BCATs unregulated activity and is not neccesary for $\mathrm{BC}$ ester synthesis per se. There may also be a requirement for an increase in $\mathrm{BC}$ $\alpha$-keto decarboxylase and dehydrogenase activities as well, likely following the increase in the capacity for $\mathrm{BC} \alpha$-keto acid synthesis. In support of this possibility, transcriptomic analysis of ripening banana fruit has revealed a more than 10-fold increase in a BC $\alpha$-keto decarboxylase (Asif et al., 2014). More detailed analyses of these final steps in the synthetic pathway for $\mathrm{BC}$ esters would be helpful in furthering our understanding of this pathway central to the formation of the characteristic aroma of banana. 


\section{Literature Cited}

Asif, M.H., D. Lakhwani, S. Pathak, P. Gupta, S.K. Bag, P. Nath, and P.K. Trivedi. 2014. Transcriptome analysis of ripe and unripe fruit tissue of banana identifies major metabolic networks involved in fruit ripening process. BMC Plant Biol. 14:316-331.

Azevedo, R.A., P. Arruda, W.L. Turner, and P.J. Lea. 1997. The biosynthesis and metabolism of the aspartate derived amino acids in higher plants. Phytochemistry 46:395-419.

Baldwin, I.T., A. Kessler, and R. Halitschke. 2002. Volatile signaling in plant-plant-herbivore interactions: What is real. J. Curr. Opin. Plant Biol. 5:351-354.

Beaudry, R.M., A.C. Cameron, A. Shirazi, and D. Dostal-Lange. 1992. Modified atmosphere packaging of blueberry fruit: Effect of temperature on package oxygen and carbon dioxide. J. Amer. Soc. Hort. Sci. 117:436-441.

Beaudry, R.M., N. Paz, C.C. Black, and S.J. Kays. 1987. Banana ripening: Implications of changes in internal $\mathrm{CO}_{2}$ and ethylene concentrations, pulp fructose 2,6-bisphosphate and activity of some glycolytic enzymes. Plant Physiol. 85:277-282.

Beaudry, R.M., R.F. Severson, C.C. Black, and S.J. Kays. 1989. Banana ripening: Implication of changes in glycolytic intermediate concentration, glycolytic and gluconeogenic carbon flux, and fructose 2,6-bisphosphate concentration. Plant Physiol. 91:1436-1444.

Brady, C.J., J.K. Palmer, P.B.H. O'Connell, and R.M. Smillie. 1970. An increase in protein synthesis during ripening of the banana fruit. Phytochemistry 9:1037-1047.

Contreras, C., H. Tjellström, and R.M. Beaudry. 2015. Relationships between free and esterified fatty acids and LOX-derived volatiles during ripening in apple. Postharvest Biol. Technol. 112:105-113.

de Kraker, J. and J. Gershenzon. 2011. From amino acid to glucosinolate biosynthesis: Protein sequence changes in the evolution of methylthioalkylmalate synthase in arabidopsis. Plant Cell 23:38-53.

Eisenstein, E. 1991. Cloning, expression, purification, and characterization of biosynthetic threonine deaminase from Escherichia coli. J. Biol. Chem. 266:5801-5807.

Emaga, T.H., R.H. Andrianaivo, B. Wathelet, J.T. Tchango, and M. Paquot. 2007. Effects of the stage of maturation and varieties on the chemical composition of banana and plantain peels. Food Chem. 103:590-600.

Ferreira, L., R. Perestrelo, M. Caldeira, and J.S. Câmara. 2009. Characterization of volatile substances in apples from Rosaceae family by headspace solid-phase microextraction followed by GCqMS. J. Sep. Sci. 32:1875-1888.

Ge, Y., K.-D. Hu, S.-S. Wang, L.-Y. Hu, X.-Y. Chen, Y.-H. Li, Y. Yang, F. Yang, and H. Zhang. 2017. Hydrogen sulfide alleviates postharvest ripening and senescence of banana by antagonizing the effect of ethylene. PLoS One 12(6):e0180113, doi: 10.1371/journal.pone.0180113.

Gonda, I., E. Bar, V. Portnoy, S. Lev, J. Burger, A.A. Schaffer, Y. Tadmor, S. Gepstein, J.J. Giovannoni, N. Katzir, and E. Lewinsohn. 2010. Branched-chain and aromatic amino acid catabolism into aroma volatiles in Cucumis melo L. fruit. J. Expt. Bot. 61:1111-1123. Guadagni, D., J. Bomben, and J. Hudson. 1971. Factors influencing the development of aroma in apple peels. J. Sci. Food Agr. 22:110-115. Hulme, A.C. 1954. The isolation of L-citramalic acid from the peel of the apple fruit. Biochim. Biophys. Acta 14:36-43.

Inaba, A., X. Liu, N. Yokotani, M. Yamane, W.-J. Lu, R. Nakano, and Y. Kubo. 2007. Differential feedback regulation of ethylene biosynthesis in pulp and peel tissues of banana fruit. J. Expt. Bot. 58:1047-1057.

Jayanty, S., J. Song, N.M. Rubinstein, A. Chong, and R.M. Beaudry. 2002. Temporal relationship between ester biosynthesis and ripening events in bananas. J. Amer. Soc. Hort. Sci. 127:998-1005.

Ji, L. and G. Srzednicki. 2015. Extraction of aromatic compounds from banana peels. Acta Hort. 1088:541-546.

Jordan, M.J., K. Tandon, P.E. Shaw, and K.L. Goodner. 2001. Aromatic profile of aqueous banana essence and banana fruit by gas chromatography-mass spectrometry (GC-MS) and gas chromatographyolfactometry (GC-O). J. Agr. Food Chem. 49:4813-4817.
Kroumova, A.B. and G.J. Wagner. 2002. Different elongation pathways in the biosynthesis of acyl groups of trichome exudate sugar esters from various solanceous plants. Planta 216:10131021.

Martin, G., F.-C. Baurens, G. Droc, M. Rouard, A. Cenci, A. Kilian, A. Hastie, J. Doležel, J.-M. Aury, A. Alberti, F. Carreel, and A. D’Hont. 2016. Improvement of the banana "Musa acuminata" reference sequence using NGS data and semi-automated bioinformatic methods. BMC Genomics 17(243):1-12.

Mourad, G. and J. King. 1995. L-O-Methylthreonine-resistant mutant of Arabidopsis defective in isoleucine feedback regulation. Plant Physiol. 107:43-52.

National Institute of Standards and Technology. 2011. NIST Chemistry WebBook, SRD 69. 12 July 2018. <http://webbook.nist.gov/ chemistry/name-ser.html>.

Ning, J., G.D. Moghe, B. Leong, J. Kim, I. Ofner, Z. Wang, C. Adams, A.D. Jones, D. Zamir, and R.L. Last. 2015. A feedback-insensitive isopropylmalate synthase affects acylsugar composition in cultivated and wild tomato. Plant Physiol. 169:1821-1835.

Nogueira, J.M.F., P.J.P. Fernandes, and A.M.D. Nascimento. 2003. Composition of volatiles of banana cultivars from Madeira Island. Phytochem. Anal. 14:87-90.

Ogata, T. and S. Miyashita. 2014. Isolation and pilot-scale evaluation of isoamyl alcohol-overproducing mutants of bottom-fermenting brewing yeasts. J. Amer. Soc. Brew. Chem. 72:110-115.

Pérez, A.G., J.J. Rios, C. Sanz, and J.M. Olías. 1992. Aroma components and free amino acids in strawberry variety Chandler during ripening. J. Agr. Food Chem. 40:2232-2235.

Pérez, A.G., R. Olias, P. Luces, and C. Sanz. 2002. Biosynthesis of strawberry aroma compounds through amino acid metabolism. J. Agr. Food Chem. 50:4037-4042.

Quast, S.V. 1976. Constituentes da banana Madura (Musa cavendishii, variedade Valery). Cienc. Cult. 28:348-352.

Reineccius, G. 2006. Flavor formation in fruits and vegetables. 2nd ed. CRC Press, Boca Raton, FL.

Rowan, D.D., H.P. Lane, J.M. Allen, S. Fielder, and M.B. Hunt. 1996. Biosynthesis of 2-methylbutyl, 2-methyl-2-butenyl, and 2methylbutanoate esters in Red Delicious and Granny Smith apples using deuterium-labeled substrates. J. Agr. Food Chem. 44:3276-3285.

Rowan, D.D., H.P. Lane, M.B. Hunt, and J.M. Allen. 1998. Metabolism of amino acids into aroma volatiles by five apple cultivars. Acta Hort. 464:490.

Salunkhe, D.K. and J.Y. Do. 1976. Biogenesis of aroma constituents of fruits and vegetables. Crit. Rev. Food Sci. Nutr. 8:161-190.

Sanz, C., J.M. Olias, and A.G. Perez. 1997. Aroma biochemistry of fruits and vegetables, p. 125-155. In: F.A. Tomás-Barberán and R.J. Robins (eds.). Phytochemistry of fruit and vegetables. Oxford Univ. Press, New York, NY.

Schieberle, P., S. Ofner, and W. Grosch. 1990. Evaluation of potent odorants in cucumbers (Cucumis sativus) and muskmelons (Cucumis melo) by aroma extract dilution analysis. J. Food Sci. 55:193195.

Schiota, H. 1993. New esteric components in the volatiles of banana fruit (Musa sapientum L.). J. Agr. Food Chem. 41:2056-2062.

Seymour, G.B. 1993. Banana, p. 83-106. In: G.B. Seymour, J.E. Taylor, and G.A. Tucker (eds.). Biochemistry of fruit ripening. Chapman and Hall, New York, NY.

Singh, B.K. and D.L. Shaner. 1995. Biosynthesis of branched chain amino acids: From test tube to field. Plant Cell 7:935-944.

Sugimoto, N., A.D. Jones, and R. Beaudry. 2011. Changes in free amino acid content in 'Jonagold' apple fruit as related to branchedchain ester production, ripening, and senescence. J. Amer. Soc. Hort. Sci. 136:429-440.

Sugimoto, N., P. Forsline, and R. Beaudry. 2015. Volatile profiles of members of the USDA Geneva Malus core collection: Utility in evaluation of a hypothesized biosynthetic pathway for esters derived from 2-methylbutanoate and 2-methylbutanol. J. Agr. Food Chem. 63:2106-2116. 
Sugimoto, N., S. Park, S. van Nocker, and R. Beaudry. 2008. Gene expression associated with apple aroma biosynthesis. Acta Hort. 768:57-64.

Tewari, Y.B., R.N. Goldberg, and J.D. Rozzell. 2000. Thermodynamics of reactions catalysed by branched-chain-amino-acid transaminase. J. Chem. Thermodyn. 32:1381-1398.

Tressl, R. and F. Drawert. 1973. Biogenesis of banana volatiles. J. Agr. Food Chem. 21:560-565.

Tressl, R. and W.G. Jennings. 1972. Production of volatile compounds in the ripening banana. J. Agr. Food Chem. 20:189-192.

Wessel, P., E. Graciet, R. Douce, and R. Dumas. 2000. Evidence for two distinct effector-binding sites in threonine deaminase by sitedirected mutagenesis, kinetic, and binding experiments. Biochem. 39:15136-15143.

Wyllie, S.G. and J.K. Fellman. 2000. Formation of volatile branched chain esters in bananas (Musa sapientum L.). J. Agr. Food Chem. 48:3493-3496.
Wyllie, S.G., D.N. Leach, H.N. Nonhebel, and I. Lusunzi. 1996. Biochemical pathways for the formation of esters in ripening fruit, p. 52-57. In: A.J. Taylor and D.S. Mottram (eds.). Flavour science, recent developments. Royal Soc. Chem., Cambridge, UK.

Xing, A. and R. Last. 2017. A regulatory hierarchy of the arabidopsis branched-chain amino acid metabolic network. Plant Cell 29:14801499.

Yoo, H., J. Widhalm, Y. Qian, H. Maeda, B. Cooper, A. Jannasch, I. Gonda, E. Lewinsohn, D. Rhodes, and N. Dudareva. 2013. An alternative pathway contributes to phenylalanine biosynthesis in plants via a cytosolic tyrosine:phenylpyruvate aminotransferase. Nat. Commun. 4:1-11.

Yoshioka, H., Y. Ueda, and T. Iwata. 1982. Development of isoamyl acetate biosynthetic pathway in banana fruit during ripening and suppression in its development at high temperature. Physiological studies of fruit ripening in relation to heat injury. Nippon Shokuhin Kogyo Gakkaishi 29:333-339. 